\title{
Identificando mudanças de regimes sistêmicos em processos econômicos: um procedimento baseado na abordagem de dinâmica de sistemas
}

\author{
Newton Paulo Bueno**
}

\section{Resumo}

A tese deste trabalho é que as técnicas mais sofisticadas atualmente utilizadas pelos economistas para fazer previsões (métodos não estruturais de previsão, em geral, e modelos de detecção de mudanças de regime, em particular) não parecem realmente muito eficazes em prever mudanças radicais de regime como a que ocorreu na economia mundial recentemente. Assim, para aumentar seu grau de acurácia, parece razoável imaginar que tais técnicas devam ser complementadas por abordagens mais holísticas. O objetivo geral deste trabalho é mostrar que a metodologia de dinâmica de sistemas (system dynamics), que permite identificar os ciclos de feedback que comandam a dinâmica de sistemas complexos, parece estar especialmente bem-equipada para se tornar uma dessas abordagens complementares. Pretende-se, especificamente, apresentar um algoritmo sistêmico para identificar processos de mudança de regime como os que ocorrem quando uma economia, após anos de expansão continuada, sofre os efeitos da explosão de uma bolha financeira, como ocorreu recentemente.

Palavras-chave: Modelos de mudança de regime; Dinâmica de sistemas; Ciclos de feedback; Macroeconomia; Modelos de crescimento.

\section{Abstract \\ Identifying systemic regime shifts in economic processes: a procedure based on the system dynamics approach}

This paper argues that the sophisticated techniques presently used by economists to forecast macroeconomic variables behavior (non-structural forecasting methods, in general, and regimeswitching models, in particular) do not seem much effective for anticipating radical regime shifts as recently happened in the world economy. Thus, in order to improve their accuracy, it seems that they should be complemented by more holistic approaches. The general purpose of the paper is to show that the system dynamics methodology, which allows identifying the critical feedback loops that drive complex systems' dynamics, seems to be especially fitted to be one of those complementary approaches. To reach that goal, we present a systemic algorithm which allows identifying regime shift processes as the ones that take place when an economy is hit by the effects of a financial bubble burst.

Key-words: Regime-switching models; System dynamics; Loop dominance analysis; Macroeconomics; Economic growth models.

JEL C63, E27, E37.

\footnotetext{
* Trabalho recebido em 8 de abril de 2009 e aprovado em 12 de abril de 2012.

** Professor do Departamento de Economia, área de Macroeconomia e Instituições da Universidade Federal de Viçosa, Viçosa, MG, Brasil. E-mail: npbueno@ufv.br.
} 


\section{Introdução}

A crise atual tem suscitado naturalmente a questão de se as sofisticadas técnicas econométricas atualmente empregadas pelos economistas são realmente úteis para ajudar a prever mudanças de conjuntura tão drásticas como a que ocorreu em meados de 2008. A conjectura deste trabalho é que, por não se alicerçarem em modelos teóricos explícitos, tais técnicas (métodos não estruturais de previsão, em geral, e modelos de detecção de mudanças de regime, em particular) não parecem de fato muito eficazes em prever mudanças radicais de regime e, portanto, talvez devam ser complementadas por abordagens mais holísticas para aumentar a acurácia de suas previsões. O objetivo geral deste trabalho é mostrar que a metodologia de dinâmica de sistemas (system dynamics), que permite identificar os ciclos de feedback que comandam a dinâmica de sistemas complexos, parece estar especialmente bem equipada para se tornar uma dessas abordagens complementares. Pretende-se, especificamente, apresentar um algoritmo sistêmico para identificar processos de mudança de regime como as que ocorrem quando uma economia, após anos de expansão continuada, sofre os efeitos da explosão de uma bolha financeira, como ocorreu recentemente. Antes de apresentar a contribuição específica do trabalho, entretanto, é conveniente resumir o estado da arte na matéria.

Os modelos que incorporam mudanças de regime (regime-switching) têm uma longa tradição em econometria dinâmica (ver Diebold e Rudebusch, 1996). Um das mais recentes versões desse tipo de modelo são os modelos de thresholds, nos quais o regime muda de acordo com a história passada observada do sistema (ver, por exemplo, Potter, 1995). Outra classe de modelos, considerada potencialmente mais adequada para estudar mudanças de regime ao longo do ciclo econômico, procura detectar estados latentes em vez de inferir tais estados ou thresholds diretamente dos dados observados (Diebold, 1998). A ideia central desses últimos modelos é que expansões e contrações no nível de atividade podem ser tratadas como objetos probabilísticos; para caracterizar mais claramente a contribuição que se pretende dar neste trabalho, talvez valha a pena descrever um pouco mais detalhadamente essa metodologia, com base no trabalho seminal de Hamilton (1989), que deu origem às várias versões de modelos de mudança de regime utilizadas em previsão macroeconômica atualmente.

O produto agregado é modelado como a soma de uma cadeia de Markov e de uma autorregressão Gaussiana, como a seguir:

$$
Y_{t}=Z_{t}+X_{t}
$$

Onde

$$
Z_{t}=\alpha_{0}+\alpha_{1} S_{t}, \quad S_{t}=0 \text { or } 1
$$


Em que $\mathrm{S}_{\mathrm{t}}$ representa dois estados do sistema, por exemplo expansão e recessão, com probabilidades de transição dadas pela matriz a seguir.

$$
M=\left[\begin{array}{lc}
p_{00} & 1-p_{00} \\
1-p_{11} & p_{11}
\end{array}\right]
$$

Sendo que o $\mathrm{ij}^{\text {th }}$ elemento de $\mathrm{M}$ representa a probabilidade de movimento do estado i (no período t-1) para o estado $\mathrm{j}$ (no período t). Os parâmetros $\mathrm{p}_{00} \mathrm{e} \mathrm{p}_{11}$, isto é, a probabilidade de permanecer em recessão ou expansão, são estimados conjuntamente com os parâmetros da autorregressão para $\mathrm{X}$ :

$$
X_{t}=\phi_{1} X_{t-1}+\phi_{2} X_{t-2}+\phi_{3} X_{t-3}+\phi_{4} X_{t-4}+\sigma V_{t}
$$

As estimativas para $p_{00}$ e $p_{11}$ permitem calcular a probabilidade de permanecer em uma recessão uma vez que a economia encontre-se nesse estado, isto é, a duração esperada de uma recessão como:

$$
\sum_{k=1}^{\infty} k p_{00}^{k-1}\left(1-p_{00}\right)=\left(1-p_{00}\right)^{-1}
$$

e a duração média esperada de uma expansão, como $\left(1-\mathrm{p}_{11}\right)^{-1}$.

Isto é, o procedimento permite computar limiares de mudança de regime (turning points) para a série de produto, na medida em que, sabendo que uma recessão dura em média 4,7 trimestres e uma expansão 10,5 trimestres (valores estimados por Hamilton para os EUA entre 1953 e 1982), poder-se-ia inferir a partir da situação atual, isto é, de quantos trimestres a economia encontra-se em expansão ou recessão, o momento da próxima mudança de regime.

O problema com essa metodologia, como em todos os métodos não estruturais de previsão, é que ela assumidamente prescinde de modelos teóricos para gerar suas previsões ${ }^{1}$. As informações sobre mudanças de regime são extraídas do comportamento passado da própria série, utilizadas para estimar os parâmetros do modelo e assim são incorporadas para prever futuras mudanças de regime. As razões de porque ocorrem turning points são deixadas sem explicação, a não ser pelo fato de que as mudanças de regime ocorrem segundo uma dinâmica comum sobre a qual, entretanto, sabemos pouco teoricamente.

Vários trabalhos recentes em dinâmica de sistemas têm se dedicado a estudar os processos de mudanças de regime em sistemas complexos, focalizando as causas dessas mudanças. Rudolph e Repenning (2002), por exemplo, mostram que a acumulação de eventos rotineiros pode levar um sistema ao colapso, uma vez que seja ultrapassado um limiar, a partir do qual ciclos de feedback

(1) O título de um importante paper por Sargent e Sims (1977) - "Business cycle modeling without pretending to have too much a priori theory" - resume o espírito desses modelos. 
autorreforçantes levam uma organização a perder eficiência em resolver problemas operacionais. Taylor e Ford (2006) explicam por que o acúmulo de tarefas na fase de desenvolvimento de novos projetos em uma organização pode gerar efeitos de onda (ripple effects) na fase de conclusão desses projetos e assim levá-los ao fracasso. Sengupta et al. (2001), em outro contexto, mostram que sistemas de irrigação podem entrar em trajetórias de perda de sustentabilidade ao se reduzirem os gastos de manutenção dos equipamentos. Ford (1996), finalmente, sugere que empresas de eletricidade podem ser aprisionadas em uma espiral de prejuízos se expandirem sua capacidade à frente da demanda além de um certo nível crítico.

A ideia básica desses trabalhos é que mudanças de regime ocorrem quando sistemas ultrapassam certos limiares em que ocorrem mudança de dominância de ciclos de feedback. Nesses momentos, processos de crescimento comandados por ciclos de feedback virtuosos podem transformar-se em trajetórias de declínio, dominadas por ciclos viciosos de feedback. O objetivo específico deste texto é mostrar como construir algoritmos para computar tipping points, definidos como pontos em que ocorrem alterações de dominância dos ciclos (loops) de feedback que controlam um processo (Sterman, 2000). Espera-se com isso contribuir com uma abordagem alternativa para o desenvolvimento de modelos de mudanças de dominância de regime como os descritos no início desta seção.

O restante do texto está estruturado do seguinte modo. Na seção 1, apresenta-se rapidamente o conceito de sistema complexo, que compreende o sistema econômico, e explica-se por que, utilizando um modelo simples, a dinâmica de sistemas parece especialmente equipada para estudar o comportamento desse tipo de sistema. Na seção 2, apresenta-se um resumo da teoria de Minsky que se considera de aplicabilidade bastante geral para descrever crises financeiras como processos de ultrapassagem de tipping points. Na seção 3, apresenta-se um procedimento para identificar tipping points e mudanças de dominância de ciclos de feedback. A seção 4 desenvolve um modelo sistêmico para a teoria de Minsky apresentada na seção 2 e aplica o procedimento descrito na seção anterior para a detecção de tipping points em períodos de deflagração de crises econômicas. A última seção conclui o trabalho, resumindo os principais resultados, esclarecendo suas limitações mais importantes e sugerindo como ele pode contribuir para a análise das crises econômicas.

\section{Sistemas complexos e dinâmica de sistemas}

Sistemas são conjuntos de elementos organizados intencionalmente pela ação humana ou que simplesmente se auto-organizam para cumprir propósitos específicos. O sistema elétrico de um automóvel é um exemplo do primeiro tipo e uma biota não explorada por seres humanos, um exemplo do segundo tipo de sistemas. Os sistemas econômicos são de um terceiro tipo que envolve tanto 
elementos de intencionalidade quanto de auto-organização. Os três tipos de sistemas podem exibir graus consideráveis de complexidade, mas apenas os do segundo e do terceiro tipo definem-se como sistemas dinamicamente complexos. Complexidade dinâmica é uma propriedade que decorre do fato de que em sistemas que a exibem encontram-se presentes diferentes agentes que respondem a informações exógenas ou geradas pelo próprio comportamento do sistema, e assim o sistema pode responder de forma não intencional do ponto de vista dos agentes que tentam influir sobre ele, isto é, o sistema pode se auto-organizar. É fácil ver então que sistemas caracterizados por extrema complexidade de detalhes podem ser dinamicamente simples na medida em que não envolvam agentes capazes de responder a novas informações e sistemas relativamente simples em termos de detalhes podem ser dinamicamente complexos.

Um sistema de navegação automática de aviões, por exemplo, envolve um enorme número de componentes sofisticados, interligados em redes de controle simultâneo, em que novas informações, como variações climáticas ou consumo anormal de combustível, são imediatamente utilizadas para calibrar o funcionamento desses componentes, ajustando a rota de viagem e a velocidade adotadas. Mas o sistema, em si, não é dinamicamente complexo, enquanto não considerarmos um componente adicional, os pilotos. Em um sistema teoricamente independente da ação humana, as respostas do sistema estariam pré-programadas e seriam sempre as mesmas em condições semelhantes. Ao considerarmos a presença de agentes, introduzimos complexidade dinâmica no sistema de navegação. $O$ agente pode responder de forma contrária ao esperado pelos projetistas do sistema de navegação, tornando-se, por exemplo, menos atento a informações que não são processadas pelo sistema automático. Um caso famoso ocorrido no Brasil foi o de um piloto da antiga Vasp que programou a rota erradamente no navegador automático e, confiante na infalibilidade do equipamento, deixou de considerar uma série de outras informações visuais e mesmo advertências de passageiros experientes que perceberam que o avião estava fazendo um trajeto diferente do usual. A confiança no equipamento era tamanha que, somente quando já não era possível corrigir o erro, o piloto finalmente decidiu procurar por um local alternativo para um pouso de emergência, acabando por aterrissar em plena floresta amazônica.

Este evento é extremamente comum e de fato pode ser considerado como uma propriedade de sistemas complexos, sendo conhecido como lei das consequências não intencionais. Tais consequências ocorrem porque, em sistemas dinamicamente complexos, as decisões individuais encontram-se interligadas em malhas de retroalimentação (feedback), o que torna a auto-organização possível.

Sistemas dinamicamente simples podem também evidentemente envolver ciclos de feedback, como no caso de um aparelho de ar condicionado que mantém a 
temperatura pré-programada em um ambiente, mas, se devidamente projetados, não são capazes de gerar consequências não pretendidas, a não ser em caso de falha do equipamento. Já em sistemas dinamicamente complexos, em que decisões são tomadas por pessoas agindo em condições de racionalidade limitada, como no caso do avião acidentado acima, consequências não intencionais podem facilmente ocorrer, pelo simples fato de que, por exemplo, o piloto julga que o sistema de navegação seja tão seguro que não precisa tomar precauções básicas, como olhar para o solo e verificar se está no rumo certo.

A dinâmica de sistemas (system dynamics) é uma metodologia desenvolvida exatamente para rastrear as consequências de ações isoladas sobre o comportamento de variáveis que encontram-se interligadas em malhas de feedback, em que as relações entre causas e consequências estão geralmente distanciadas no tempo, isto é, em que as variáveis relacionam-se com defasagens temporais normalmente não captadas em nossos modelos mentais ${ }^{2}$.

A metodologia de dinâmica de sistemas pode assim ser definida sinteticamente como abordagem informação/ação/consequências, como representado na figura a seguir ${ }^{3}$ :

Figura 1

A abordagem de dinâmica de sistemas

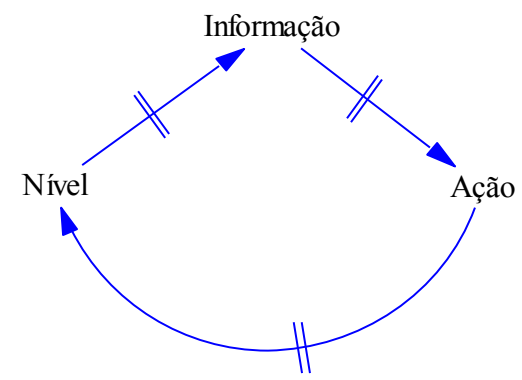

Novas informações levam a ações (fluxos) que alteram o estado (nível) das condições de um sistema após uma defasagem de tempo (as duas marcas paralelas sobre a seta indicam a presença de um retardo - delay - temporal entre a execução da ação e a mudança no estado do sistema). Ação, nível e informação interligam-se em dois tipos de ciclos de feedback. O primeiro tipo é o ciclo de feedback negativo

(2) As técnicas incluídas nessa metodologia começaram a ser desenvolvidas pelo pesquisador do Massachusetts Institute of Technology Jay Forrester nas décadas de 1950 e 1960, em uma série de estudos clássicos sobre economia regional e urbana e vêm sendo empregadas em estudos aplicados em campos tão distintos do conhecimento como política internacional, ecologia, gestão de recursos naturais e economia. Uma bibliografia de referência básica pode ser obtida em http://www.systemdynamics.org/short bibliography.htm. Uma referência básica para uma visão abrangente da metodologia e das principais técnicas é Sterman (2000).

(3) Ver Coyle (1996) 
ou de equilíbrio em que o sistema reage a mudanças compensando-as. O segundo tipo é o ciclo de feedback positivo ou de autorreforço, em que o sistema amplifica eventuais perturbações.

Em seu fascinante livro sobre epidemias comportamentais, Malcolm Gladwell (2000) explica por que a lógica das epidemias de doenças pode ajudar a compreender episódios sociais em que determinados comportamentos podem se difundir pela sociedade, por meio de ciclos de feedback de autorreforço, de modo muito semelhante a epidemias de gripe. Para ilustrar o argumento, o autor usa um exemplo informal de como epidemias desse tipo podem se originar a partir de uma pequena variação das condições iniciais de um sistema. Usemos esse exemplo para ilustrar como um sistema simples em termos de detalhes pode apresentar uma dinâmica inesperadamente complexa.

O exemplo é o seguinte (p. 281, nota relativa à página 12): suponha-se que 1.000 canadenses cheguem a Manhattan em um dia de verão infectados por um vírus que vive por 24 horas. Suponha-se ainda que o grau de infecciosidade seja de $2 \%$, isto é, que uma em cada 50 pessoas que entrem em contato próximo seja infectada pelo vírus, e que o número de pessoas com que um cidadão entra em contato próximo por dia - a taxa de contato - seja em média de 50. Nesse caso, usando uma argumentação puramente aritmética, o autor mostra que uma epidemia não se desenvolverá. Contudo, se a taxa de contato for um pouco maior, digamos de 55, como ocorre no inverno em que as pessoas tendem a se concentrar mais em locais fechados, como em ônibus e metrôs, o mesmo número de canadenses gripados poderia ser suficiente para iniciar uma epidemia de gripe. É fácil desenvolver um modelo sistêmico simples que ajuda a entender melhor o processo; o modelo na Figura 2 é o mais simples possível.

A variável de nível ou estoque população suscetível de ser infectada pelo vírus (representada no interior de um retângulo) pode ser definida como o total da população da ilha, cerca de 1,5 milhão de pessoas. Quanto maiores forem os parâmetros taxa de contato e grau de infecciosidade do vírus, maior será o fluxo de pessoas infectadas por dia e maior a parcela da população que será atingida pela gripe. A população total aparece no modelo com sinal negativo porque, quanto maior for essa população em relação à parcela da população suscetível de ser infectada, menor será a possibilidade de alguém já infectado encontrar-se com um indivíduo que faça parte do grupo de risco, isto é, da população que não está imunizada à variedade específica do vírus ${ }^{4}$. Quanto maior finalmente for o período de duração média da gripe, menor o fluxo de pessoas curadas por período de tempo.

(4) O sinal negativo indica que existe uma relação inversa entre as variáveis, isto é, quando uma aumenta, a outra diminui e vice-versa. 
Figura 2

O modelo epidêmico

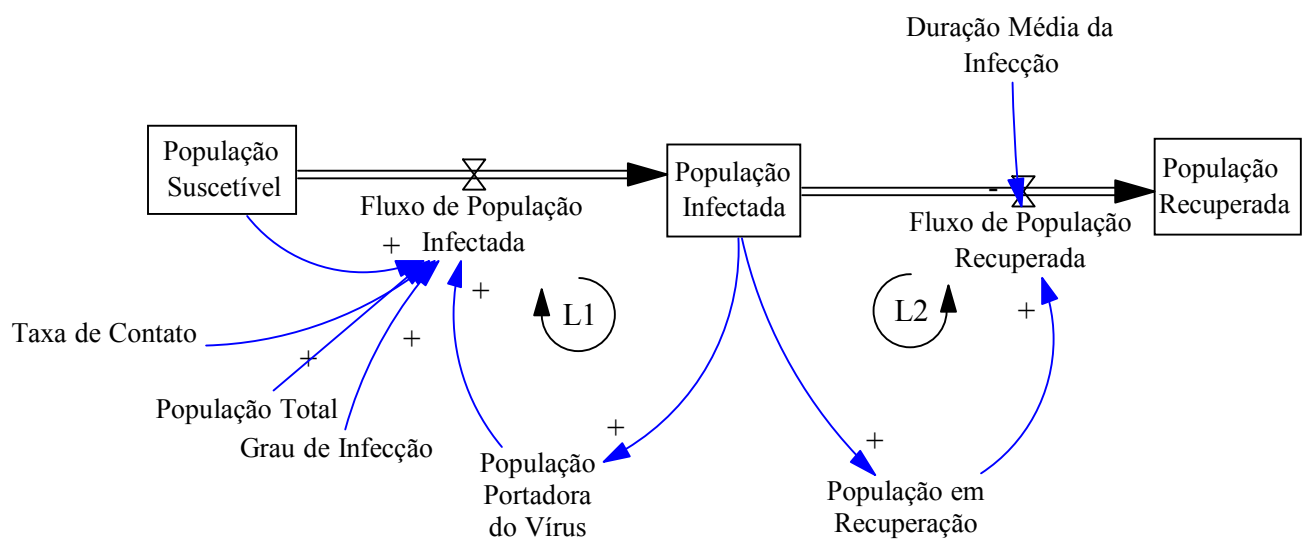

Assim, se a taxa de contato for mais baixa, como ocorre no verão, o fluxo de novas pessoas infectadas será menor do que o fluxo de canadenses que estará curado da gripe no dia seguinte, já que a duração média da doença é de 1 dia. $\mathrm{O}$ fluxo de novas pessoas infectadas, nesse caso, será então sempre menor do que o fluxo de pessoas curadas, o que significa que os casos iniciais de gripe não serão capazes de desencadear uma epidemia. A curva para "taxa de contato $=50$ " na Figura 3 ilustra essa situação.

Figura 3

Dinâmica da difusão da gripe em dois cenários

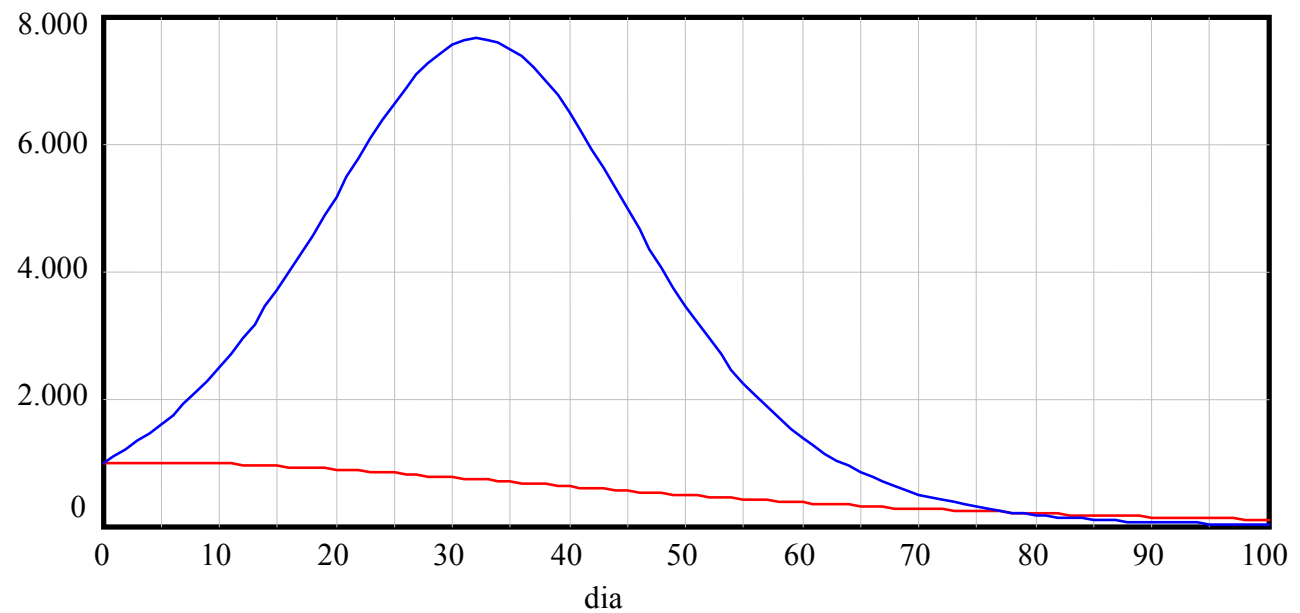

População Infectada: Taxa de Contato $=55$

População Infectada: Taxa de Contato $=50$ 
Mas se a taxa de contato for suficientemente alta, como ocorre no inverno, os portadores iniciais do vírus contaminarão alguns nova-iorquinos gerando um fluxo de pessoas infectadas maior do que o fluxo de pessoas curadas. Assim a população infectada no período seguinte será maior do que a inicial. $\mathrm{O}$ maior número de pessoas infectadas contaminará ainda mais pessoas e assim a população infectada crescerá progressivamente.

Mas há um mecanismo de estabilização em qualquer epidemia que não é tão intuitivo. À medida que mais pessoas sejam contaminadas, o número de pessoas suscetíveis de contrair a doença diminui. Assim, para uma determinada população total, a probabilidade de alguém gripado espirrar próximo a uma pessoa ainda não infectada diminui à medida que as pessoas vão se curando da gripe. Para uma mesma taxa de contato, portanto, o fato de a população suscetível de ser infectada diminuir em proporção à população total implica que o fluxo de novas pessoas contaminadas decresça. Quando esse fluxo cai abaixo do fluxo de pessoas curadas, o tamanho da população infectada começa a diminuir até que a epidemia se esgote por si mesma.

Para compreender por que uma epidemia começa e termina sem qualquer razão aparente, basta então termos uma compreensão básica da dinâmica estoquefluxo envolvida. Ocorrerá uma epidemia apenas se o fluxo de pessoas infectadas for superior ao fluxo de pessoas curadas, o que aumentará o estoque de pessoas infectadas. Neste caso a dinâmica do processo será dominada por um loop de autorreforço (L1): um maior número de pessoas infectadas leva a ainda mais pessoas infectadas. Mas o aumento desse estoque reduz o estoque de pessoas suscetíveis de serem infectadas, o que, em algum momento, tornará o fluxo de pessoas infectadas menor do que o de pessoas curadas, fazendo com que o estoque de pessoas infectadas comece a cair e finalmente se reduza a zero. Assim o sistema apresenta a partir de um certo ponto um mecanismo de autocorreção dado pelo loop de equilíbrio (L2) em que um maior número de pessoas infectadas reduz a população suscetível para uma dada população total e, portanto, o fluxo de novas pessoas infectadas.

Pode-se então dizer que existem dois pontos teóricos de mudança de regime para processos como este. Um é dado exogenamente por parâmetros do sistema tais como a taxa de contato, os quais, ultrapassados, geram epidemias. $\mathrm{O}$ outro é dado endogenamente, pelo fato de que o sistema ultrapassa espontaneamente seus limites de estabilidade. Tais limites - definidos como tipping points - são, em princípio, passíveis de serem identificados em qualquer sistema como pontos de mudança de dominância de ciclo, um conceito vital para entendermos e talvez anteciparmos situações de mudança de regime em que, para usar um exemplo da literatura de crises financeiras, uma mania transforma-se em pânico e eventualmente em crash. Na próxima seção, sugere-se como construir um 
modelo sistêmico do tipo estudado acima para estudar a dinâmica de crises financeiras.

\section{A teoria de Minsky para crises financeiras}

Uma hipótese fundamental dos modelos pós-keynesianos para as crises financeiras inspirados na teoria de Minsky é a de que a oferta de moeda é endógena. Sua disponibilidade, em outras palavras, não é dada arbitrariamente pela autoridade monetária, mas regulada pelo funcionamento do sistema econômico em conjunto. Essa endogeneidade decorre da própria evolução do sistema financeiro, que introduz progressivamente inovações financeiras, por meio de um processo de realimentação positiva com o restante dos agentes econômicos. Segundo Minsky (1982, p. 66):

Innovations in financial practices are a feature of our economy, especially when things go well. New institutions, such as Real Estate Investment Trusts (REITs), and new instruments, such as negotiable Certificates of Deposits, are developed and old instruments, such as commercial paper, increase in volume and find new uses. But each new instrument and expanded use of old instruments increases the amount of financing that is available and which can be used for financing activity and taking positions in inherited assets. Increased availability of finance bids up the prices of assets relative to the prices of current output, and this leads to increases in investment. The quantity of relevant money in a economy, in which money conforms to Keynes's definition, is endogenously determined.

Em fases de expansão cíclica, o processo de realimentação positiva acima induz elevação da proporção dos investimentos especulativos, isto é, de investimentos cujos fluxos de caixa esperados não são suficientes para saldar integralmente os financiamentos correspondentes. Já para os financiamentos de hedge, os fluxos de caixa esperados são suficientes para saldar os compromissos assumidos, não exigindo financiamento adicional posterior, visto o volume destes encontrar-se limitado pelo funcionamento dos mercados de fatores e de produtos, enquanto os primeiros dependem apenas da ampliação da disponibilidade de crédito.

O aumento da proporção de investimentos especulativos sobre investimentos garantidos aumenta a vulnerabilidade da economia a crises porque, nessas condições, uma inflexão no ritmo de expansão monetária por parte do sistema financeiro, por exemplo, respondendo a uma redução do volume de refinanciamento de títulos ou hipotecas pelo sistema bancário, tende a produzir um movimento cumulativo descendente. Isso acontece porque as unidades mais engajadas em investimentos especulativos dependem da rolagem das dívidas contraídas para saldar seus compromissos. Quando o sistema financeiro reduz o ritmo de expansão monetária e essas unidades mostram-se incapazes de fechar suas 
posições, ocorre uma reavaliação geral dos níveis aceitáveis de endividamento e da estrutura temporal dos passivos das unidades de financiamento (o aumento da proporção dos investimentos especulativos aumenta o prazo médio de retorno dos ativos empresariais e reduz o dos passivos), reiniciando o ciclo de realimentação positiva, agora no sentido descendente.

A hipótese de Minsky sobre a instabilidade financeira das economias modernas, em termos muito resumidos, portanto, postula que, em razão da própria evolução do sistema financeiro, os agentes relevantes são induzidos a uma posição de fragilidade financeira, assumindo uma estrutura de débito temporalmente mais curta que a estrutura de ativos. Uma pequena alteração do ritmo de produção endógena de moeda, nessas condições, é capaz de inverter o ciclo de realimentação positiva que anteriormente contribuía para a expansão econômica. A hipótese de instabilidade financeira assim contém:

... a theory of how a capitalist economy endogenously generates a financial structure which is susceptible to financial crises, and how the normal functioning of financial markets in the resulting boom economy will trigger a financial crisis (Minsky, 1982, p. 67-68).

A teoria de Minsky, em suma, explica a ocorrência de bolhas

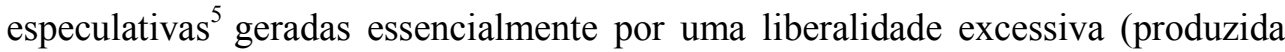
por fatores sistêmicos) quanto à oferta de moeda. Essas bolhas constituem-se na maior parte das vezes em fenômenos basicamente financeiros que tendem a esgotar-se por si próprios, embora o próprio fato de uma economia estar sujeita à ocorrência frequente dessas bolhas possa torná-la bastante instável ${ }^{6}$. Para colocar de outro modo, o importante não é o fato de ocorrerem bolhas especulativas; elas sempre existiram. O problema é que o sistema capitalista torna-se cada vez mais suscetível a apresentar essas bolhas, e portanto mais instável, com a evolução das instituições financeiras.

O diagrama de influências a seguir resume os aspectos principais da teoria das crises financeiras inspiradas em Minsky.

(5) Cohen (1997, p. 4-5) define bolhas especulativas da seguinte forma: "A speculative excess called a 'mania' implies an underlying insanity or irrationality is gripping investors, while the term 'bubble' forewarns of the inevitable bursting. It describes the entire event: the rush to an unsustainable peak, followed by the equally dramatic collapse. A bubble implies the price of an asset, or an entire market, is no longer in balance consistent with the underlying fundamental values".

(6) Sobre o efeito final das bolhas especulativas, diz Cohen (1997, p. 14): “... [in an] intriguing way most examples retrace around 80 to $99 \%$ of their previous rise, with a minimum $75 \%$ retracement as the norm. This persistent effect has given rise to the 'bubble' term... Although there is an old market adage that the boom precedes the crash, it might not seem clear as to why the mass hysteria of a boom slould often end in a 70-99 per cent retracement to create the bubble profile". 
Figura 4

O Modelo de Minsky na linguagem da dinâmica de sistemas

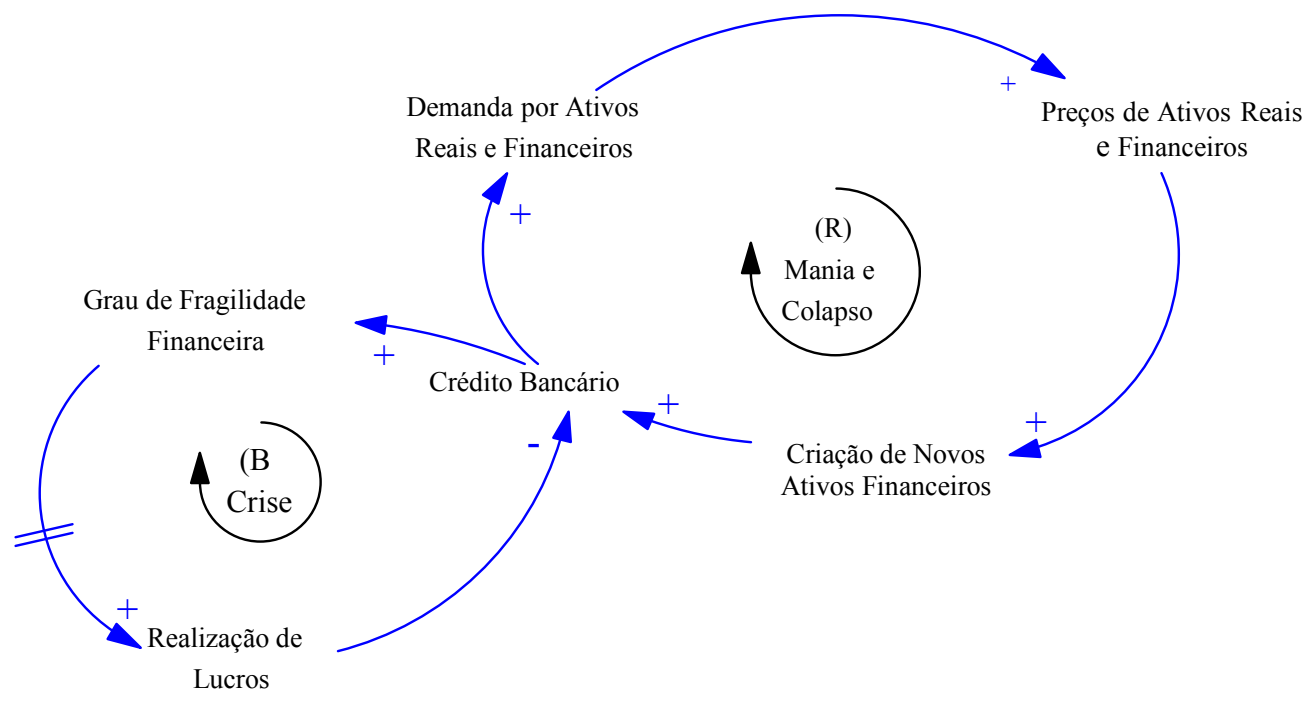

O sinal positivo sobre a seta significa que existe uma relação direta entre as variáveis e o sinal negativo, uma relação inversa; a expansão do crédito, por exemplo, leva a uma maior demanda por Ativos Reais e Financeiros e o aumento do Grau de Fragilidade Financeira, a uma maior disposição de Realização de Lucros e a um menor volume de crédito bancário. O sinal do ciclo de feedback é obtido multiplicando os sinais dos vínculos entre as variáveis, sendo positivo ou de autorreforço (R), quando o produto for positivo e de equilíbrio (B de balancing), quando o produto for negativo. O ciclo "Mania e Colapso" mostra como a oferta de crédito torna-se endógena ao sistema econômico à medida que o sistema financeiro é autorizado a criar novos ativos financeiros, por exemplo "fatiando" empréstimos originalmente destinados a financiar a aquisição de ativos reais em derivativos lastreados nos títulos de empréstimos originais. O ciclo de equilíbrio "Crise", por sua vez, mostra que a partir de certo ponto (após um delay temporal indicado pelas duas marcas sobre o vínculo) o processo ultrapassa um limiar a partir do qual começam a surgir dúvidas sobre a solvência dos devedores cujas carteiras encontram-se mais expostas a investimentos especulativos, levando à realização de lucros pelos emprestadores com recusa de novos refinanciamentos. A contração resultante no volume de crédito leva a uma desvalorização dos ativos reais e financeiros, reduzindo o valor dos colaterais colocando em ação o modo de "Colapso" do ciclo de autorreforço "Mania e Colapso" e, finalmente, provocando o estouro da bolha especulativa. O processo todo pode, então, ser visto como um processo de mudança de dominância de ciclo, com o ciclo "Mania e Colapso" dominando a dinâmica do processo durante a fase de expansão da bolha financeira 
até que o ciclo "Crise" contenha a expansão. O esvaziamento e eventual estouro da bolha acontecem após o ciclo original voltar a dominar a dinâmica do processo, desta vez no modo de "Colapso".

A questão obviamente é: haverá algum meio de identificar os intervalos para os quais cada ciclo de feedback dominará ou deixará de dominar a dinâmica do processo? Isto é, será possível prever, por exemplo, quando uma mania se transformará em pânico, da mesma forma que fomos capazes de identificar em que momento um surto de gripe no modelo epidêmico da seção 1 transforma-se em uma epidemia? Trabalhos recentes têm sugerido uma abordagem empírica para o problema, mostrando como avaliar a força de cada ciclo de feedback em cada momento do tempo e, portanto, a distância que separa um sistema particular de seus eventuais limiares de instabilidade. Na próxima seção, mostra-se como aplicar esse procedimento, utilizando-se para ilustrar a exposição o modelo epidêmico visto nesta seção.

\section{Detectando mudanças de regime sistêmico nas epidemias}

Mostrou-se na seção anterior que um sistema como o epidêmico pode experimentar mudanças significativas de comportamento quando ultrapassa tipping points. Tais pontos podem ser determinados matematicamente nesse tipo de modelo de forma direta do seguinte modo:

As equações fundamentais do modelo epidêmico são as seguintes:

$$
\frac{d \text { PopulaçãoInfectada }}{d t}=\text { FluxodePessoasInfectada.q }- \text { FluxodePessoasCuradas }
$$

Fluxo de Pessoas Infectadas ${ }_{\mathrm{t}}=$ População Suscetível $_{\mathrm{t}} \mathrm{x}$ Taxa de Contato $\mathrm{x}$ Grau de

$$
\text { Infecciosidade x } \frac{\text { PopulaçãoInfectada }}{\text { PopulaçãoTotal }}
$$

$$
\text { Fluxo de Pessoas Curadas }_{\mathrm{t}}=\frac{\text { PopulaçãoInfectada }_{t}}{\text { DuraçãoMédia da Gripe }}
$$

A equação 1 sugere que o número de pessoas infectadas crescerá sempre que o fluxo de pessoas infectadas, dado pela equação 2, for maior do que o fluxo de pessoas curadas, especificado na equação 3 , isto é, se:

População Suscetível $\mathrm{x}$ Taxa de Contato x Grau de Infecciosidade x População

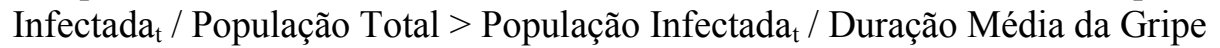
isto é, que

Supondo que toda a população da cidade seja passível de contrair a gripe,

$$
\text { População Suscetível }{ }_{\mathrm{t}}=\text { População Total }
$$

Tem-se que a condição (4) será observada para : 
Taxa de Contato > 1 / (Duração Média da Gripe x Grau de Infecciosidade)

Se a Duração Média da Gripe for de 1 dia e o grau de infecciosidade, de 0,02, o tipping point do sistema, isto é, a taxa de contato que tornará o sistema suscetível de apresentar uma epidemia será então qualquer valor superior a 50 . A visualização do que acontece no tipping point está na Figura 5.

Figura 5

Dinâmica do modelo epidêmico no tipping point PointTipping

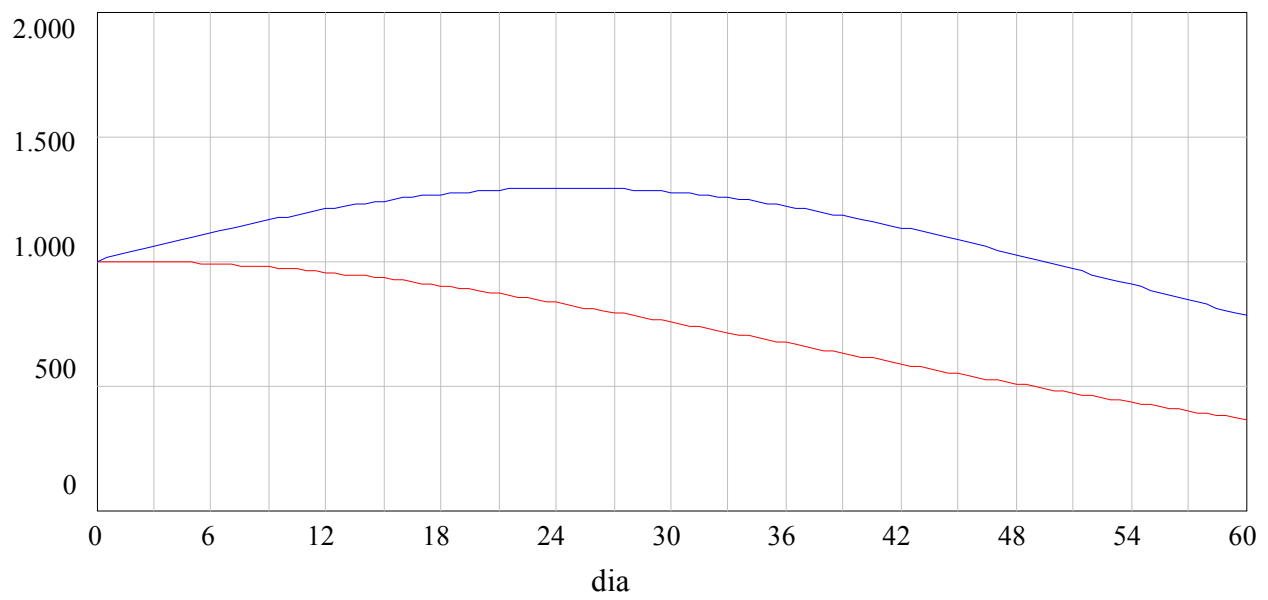

População Infectada: taxa de contato 51

População Infectada: taxa de contato 50

pessoas pessoas

A explicação de por que o modelo apresenta essa mudança de comportamento é que, para taxas de contato maiores do que 50, o sistema passa a ser comandado por um ciclo de feedback de autorreforço. A partir desse ponto, o aumento da população infectada em cada dia torna mais provável que um determinado indivíduo seja contaminado no dia seguinte, o que leva o fluxo de novas pessoas infectadas nos períodos seguintes a crescer acima do fluxo de pessoas curadas. O sistema torna-se vulnerável a apresentar um surto epidêmico, portanto, quando a taxa de contato se aproximar de seu tipping point. Isso permite deduzir que sistemas serão mais suscetíveis a epidemias ou crises econômicas, no caso de economias, quando sua dinâmica for "dominada" por ciclos de feedback autorreforçantes. Essa ideia, crucial para testar a vulnerabilidade de sistemas como a economia de um país a choques exógenos, pode ser operacionalizada usando uma metodologia simples de teste de dominância de ciclos de feedback.

Sistemas são passíveis de apresentar três tipos de comportamentos básicos em suas variáveis de interesse para o analista, por exemplo no número de pessoas infectadas por uma gripe em cada momento. O fluxo de pessoas infectadas pode crescer (ou decrescer) em padrão exponencial, crescer (ou decrescer) em padrão 
logarítmico, ou crescer (ou decrescer) linearmente, incluindo o caso particular de taxa de crescimento igual a zero. Nesses casos, a segunda derivada do estoque de pessoas infectadas (que é definida como padrão atomístico de comportamento da variável), isto é, a primeira derivada do fluxo de pessoas infectadas, será, respectivamente, positiva, negativa ou zero. Combinações desses padrões são capazes de descrever a maioria dos comportamentos apresentados por modelos de simulação. Um modelo representativo de ciclos econômicos, por exemplo, apresentará os dois primeiros tipos de padrões em diferentes momentos do tempo.

Com base no exposto, pode-se estabelecer que um ciclo de feedback domina o comportamento do sistema, durante um certo intervalo de tempo e para um conjunto particular de condições sistêmicas, quando o ciclo determina a dinâmica da segunda derivada da variável de interesse, isto é, seu padrão atomístico de comportamento. Ford (1999) propõe o seguinte algoritmo para identificar a dominância de ciclos nos mais variados tipos de sistema:

1) Identifique a variável de interesse que passará pela mudança de dominância de ciclo e simule seu comportamento no tempo.

2) Identifique um intervalo de tempo em que a variável de interesse apresente apenas um padrão atomístico de comportamento (isto é, um mesmo sinal para a segunda derivada). Esse intervalo é definido como intervalo temporal de referência.

3) Identifique um ciclo candidato, isto é, um ciclo de feedback que pode influenciar a variável de interesse.

4) Identifique ou crie uma variável de controle no ciclo que não faça parte de outros ciclos e que possa variar o ganho do ciclo candidato. Use essa variável para desativar o ciclo.

5) Simule a dinâmica da variável de interesse durante o intervalo temporal de referência com o ciclo candidato desativado e identifique o padrão atomístico de comportamento da variável de interesse durante o intervalo temporal de referência.

6) Se o padrão atomístico de referência é diferente do padrão identificado no passo 2, o ciclo testado domina o comportamento da variável de interesse sob as condições vigentes durante o intervalo temporal de referência. Se o padrão atomístico é o mesmo e não há estruturas-sombra de feedback envolvidas, o ciclo não domina a dinâmica do sistema nesse intervalo ${ }^{7}$.

(7) Estruturas-sombra de estruturas de feedback ocorrem quando dois ou mais ciclos dominam conjuntamente a dinâmica de um sistema; nesse caso, deve-se testar a ocorrência de mudança de dominância de ciclo desativando todos os ciclos envolvidos simultaneamente. Para os propósitos deste trabalho, consideramos apenas o caso mais simples onde não existem estruturas-sombra envolvidas. Para maiores detalhes sobre como identificar estruturas-sombra, ver Ford (1999, p. 18-23). 
7) Se houver outros ciclos no sistema, repita os procedimentos de 2 a 6 para os outros ciclos; caso contrário não haverá mais ciclos dominantes no período.

8) Repita os procedimentos de 2 a 7 para outros intervalos temporais de referência.

A intuição por trás desse procedimento é relativamente direta: um ciclo de feedback não dominará a dinâmica de um sistema, em um período especificado de tempo, se sua desativação não alterar a dinâmica do sistema nesse período. Ou seja, a presença ou não do referido ciclo não influenciará o comportamento do sistema em questão, se ele não for dominante.

Aplicando o algoritmo ao modelo epidêmico e considerando uma taxa de contato de 55\% para facilitar a visualização dos resultados, tem-se que:

1) Simulação da dinâmica da variável de interesse: população infectada no tempo: Figura 6.

2) Dinâmica da segunda derivada: Figura 6.

Figura 6

Dinâmica da população infectada e de sua segunda derivada

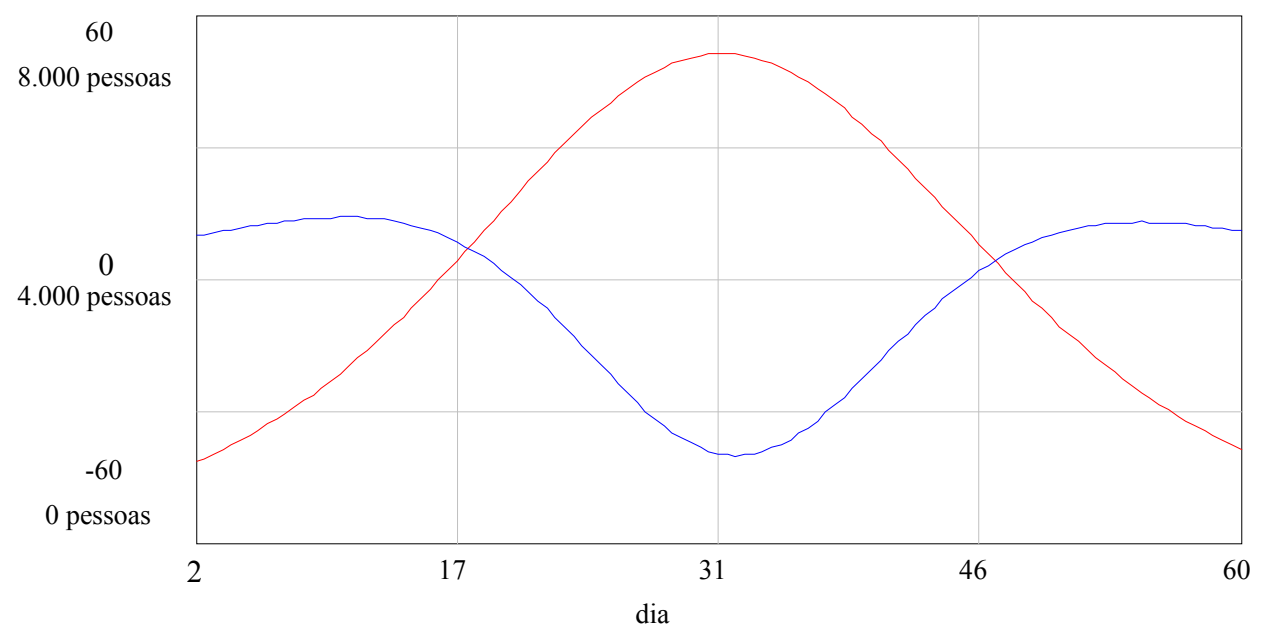

Segunda derivada: taxa de contato 55

População Infectada: taxa de contato 55

A simulação permite identificar três períodos em que o padrão de comportamento atomístico se altera: 1) 0-19,5 (comportamento atomístico exponencial, isto é, segunda derivada positiva, o que implica crescimento exponencial da população infectada); 2) 20-44,5 (comportamento atomístico negativo, ou seja segunda derivada negativa, o que implica crescimento ou declínio 
logarítmico da população infectada); 3) 45-60 (padrão exponencial ou segunda derivada positiva, implicando queda exponencial da população infectada). Escolhese para análise o período 1: do dia zero ao dia 19,5 da epidemia, definido como intervalo temporal de referência.

3) O ciclo de feedback de autorreforço L1 é escolhido como ciclo candidato.

4) O ciclo L1 é desativado criando a variável:

População Portadora do Vírus = IF THEN ELSE $\left(\right.$ Time $<\mathrm{t}_{0}$, População Infectada, $1.000)$

A qual substituirá o valor da variável População Infectada na equação (4). Isso significa que, se $\mathrm{t}_{0}=0$, o valor da População Portadora do Vírus será sempre igual a 1.000 .

5) A Figura 7 mostra a segunda derivada da variável População Infectada com o ciclo L1 desativado.

Figura 7

Segunda derivada da População Infectada com L1 desativado

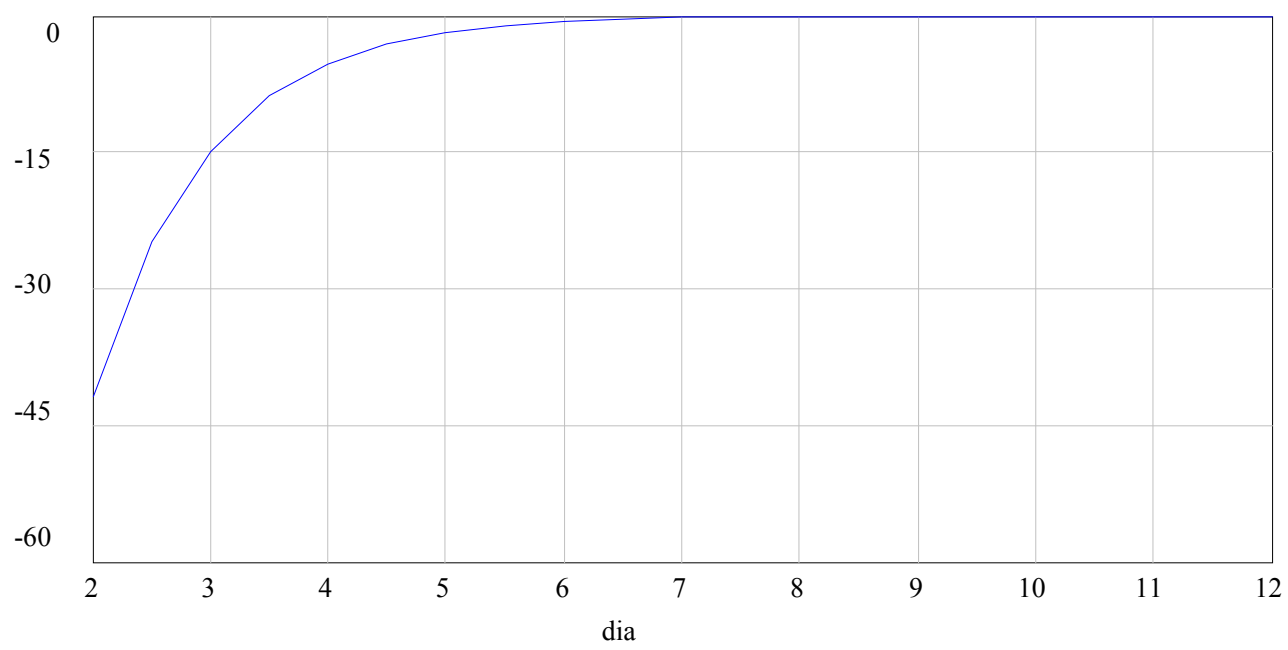

6) Os dias iniciais e finais do período foram omitidos para permitir a visualização do padrão logarítmico apresentado pela segunda derivada no período 0-12, o que indica que L1 domina nesse período em que o padrão é diferente do padrão exponencial apresentado pela segunda derivada com o ciclo L1 ativado. No restante do período, o padrão é o mesmo observado para L1 ativado, isto é, exponencial. 
7) Repetindo os procedimentos para o ciclo $\mathrm{L} 2^{8}$, conclui-se que ele não domina no período 0-7,5 e domina entre 8 e 19,5.

8) Como o interesse da discussão está na explicação dos fatores que desencadeiam as epidemias, não se examinam os demais intervalos de tempo.

A conclusão da análise é que as epidemias ocorrem quando ciclos de autorreforço como L1 dominam a dinâmica do sistema por um período relevante de tempo. A população infectada cresce endogenamente, sendo esse crescimento contido e finalmente revertido, quando o ciclo de equilíbrio L2 começa a dominar a dinâmica da epidemia. A repetição dos procedimentos acima para sistemas com taxas de contato abaixo do tipping point (50) mostra que, nesses casos em que as epidemias não chegam a se desenvolver, a dinâmica do sistema é dominada desde suas etapas iniciais pelo ciclo L2.

\section{Detectando mudanças de regime sistêmico no ciclo econômico}

A Figura 8 apresenta a estrutura estoque-fluxo de um modelo sistêmico baseado na teoria de Minsky, o qual formaliza o diagrama de influências apresentado na Figura 4. O modelo completo em versão VENSIM, disponível aos leitores mediante requisição a este autor, baseia-se no modelo em versão I-think apresentado por Paich (2010).

O modelo integra estoques e fluxos reais e monetários da economia por meio de três ciclos de feedback:

- O ciclo positivo ou de autorreforço L1 especifica a determinação da Renda nacional. O consumo é função da renda esperada, que acumula variações observadas na Renda (corrente). Investimentos e outros itens de gastos são determinados exogenamente. A demanda agregada, deduzida a correção de estoques, determina a Renda (corrente) e assim os ajustes futuros na Renda Esperada.

- O ciclo de equilíbrio L2 especifica uma modalidade de efeito riqueza. Uma redução no consumo aumenta o estoque de ativos financeiros em poder do público, elevando a riqueza e a capacidade futura de consumo.

- O ciclo de autorreforço L3 especifica um mecanismo pelo qual a fragilidade financeira da economia pode desencadear uma espiral de queda no valor de ativos reais, como imóveis. A inadimplência de tomadores de empréstimos de maior risco pode levar à execução de hipotecas e a excessos de oferta de

(8) O ciclo L2 é desativado criando a variável População em Recuperação = IF THEN ELSE (Time< $<$ t0, População Infectada, 0), com t $0=0$, e substituindo o valor da variável População Infectada na equação (4) por este valor. Assim, para qualquer dia do período (o tempo será sempre maior que zero), a população em recuperação será igual a zero, desativando a operação deste ciclo. 
imóveis, reduzindo seus valores reais. A redução do preço dos imóveis diminui o valor das garantias que os tomadores podem oferecer e dessa forma reduzir a oferta de crédito para a aquisição de novos imóveis, reforçando a queda inicial.

Figura 8

Um modelo sistêmico baseado na teoria de Minsky

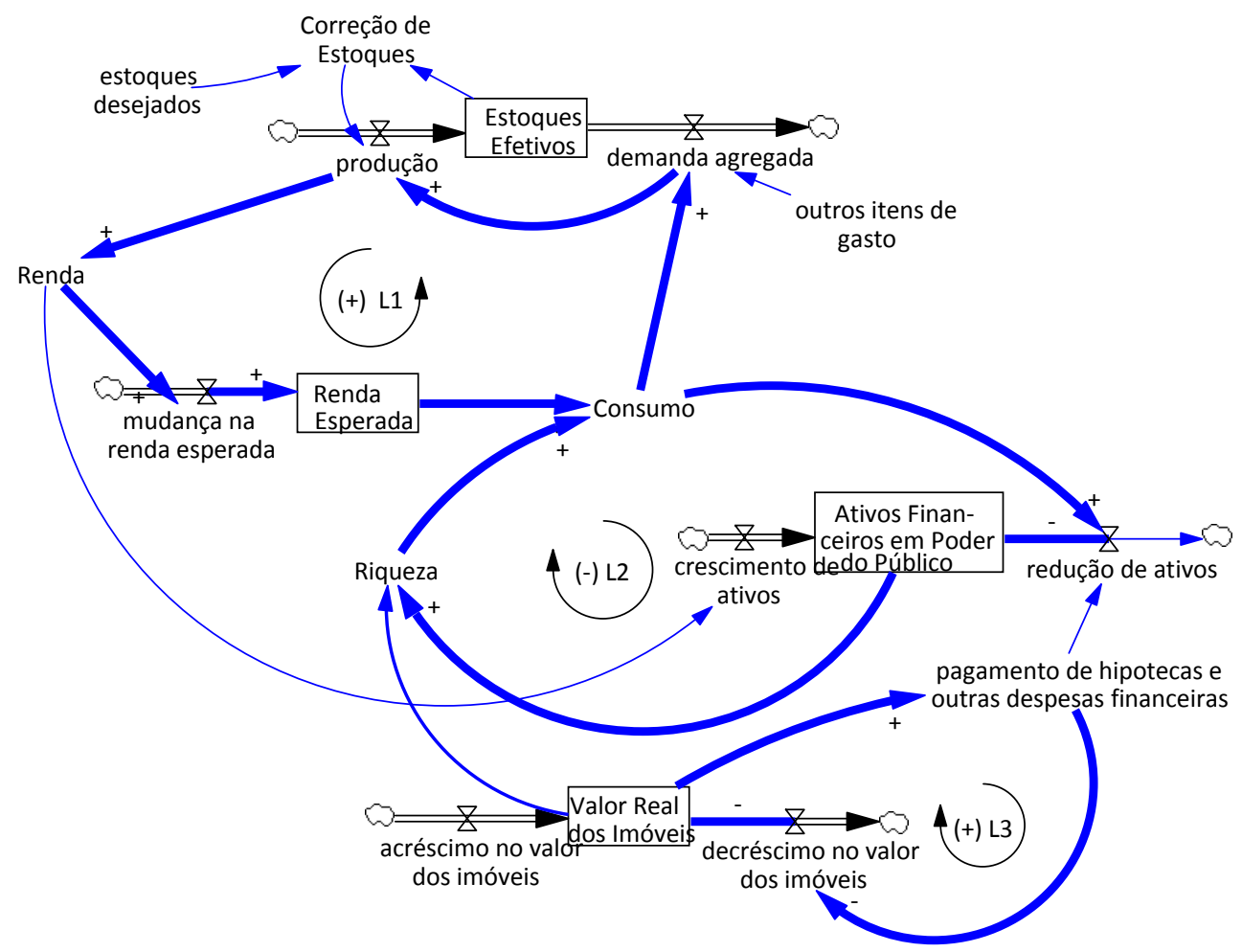

A interação desses três ciclos pode intuitivamente ajudar a compreender a essência da crise de 2008-2009. Os fatos básicos envolvidos são de amplo conhecimento $^{9}$, de modo que um breve resumo dos eventos é suficiente para estabelecer a intuição econômica do modelo.

$\mathrm{Na}$ raiz dos problemas esteve o aprofundamento de uma prática financeira denominada genericamente de securitização, por meio da qual instituições financeiras passaram a emitir, a partir do final da década de 1980, papéis de curto prazo para financiar empréstimos garantidos por hipotecas (asset-backed comercial papers). Novos papéis foram criados em uma etapa mais avançada do processo (por exemplo, collaterized debt obligations, ou CDO's), que consistiam de combinações dos primeiros e, posteriormente, de combinações de combinações,

(9) Para um resumo especialmente acessível, ver Lavoie (2009, Postface). 
denominadas de CDO's ao quadrado. Dessa forma, como indicado por Minsky, bancos com muito pouco capital tornaram-se capazes de criar uma quantidade aparentemente infinita de empréstimos baseados em hipotecas. A crescente oferta de crédito permitiu a elevação da relação débito/renda disponível e impulsionou a demanda de imóveis, elevando progressivamente seus preços. O ciclo de feedback L3 se fechava com a criação de novos papéis lastreados no maior valor dos imóveis. Os problemas começaram a aparecer quando agentes procuraram suprir sua liquidez vendendo papéis lastreados em hipotecas com maior possibilidade de default, os assim chamados empréstimos sub-prime. A execução dessas hipotecas desencadeou a espiral de queda no preço dos imóveis e redução de pagamento de hipotecas sintetizada pelo ciclo L3, agora atuando em modo decrescente.

A redução do valor dos imóveis reduziu a riqueza dos consumidores, o que levou ao declínio do consumo e da renda em um processo que se autoalimentava como mostrado pelo ciclo de autorreforço L1. A redução do consumo, entretanto, permitiu que ao menos parte dos consumidores recompusesse seus estoques de ativos financeiros, restabelecendo seus níveis de riqueza e de consumo a médio prazo, como indicado pelo ciclo de equilíbrio L2.

A questão é que a ampliação de crédito não gerou crises significativas por cerca de 20 anos. Por que isso aconteceu em 2008? Para responder a essa questão, temos de tentar identificar as condições que levam o sistema econômico a ultrapassar seus limites de segurança, o que, como no caso do modelo epidêmico da seção anterior, pode ser feito por meio de uma análise de dominância de ciclos de feedback.

Para isso, suponha-se, para simplificar a discussão, que o valor dos imóveis decresça exogenamente. Isto é, que a dinâmica do ciclo L3 possa ser representada simplificadamente pelas equações (1)-(3).

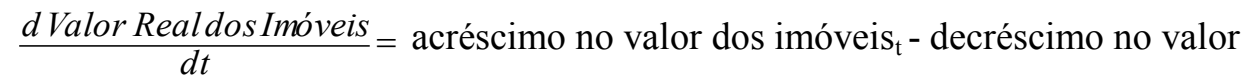
dos imóveis,

acréscimo no valor dos imóveis ${ }_{t}=0$

decréscimo no valor dos imóveis ${ }_{\mathrm{t}}=0+\operatorname{PULSE}(10,18) *$ Valor Inicial dos Imóveis*choque de preços de venda de imóveis

A equação (1) especifica o fluxo de variação do valor real dos imóveis ${ }^{10} \mathrm{e}$ as equações 2 e 3 que no mês 10 da simulação inicia-se uma queda mensal do valor dos imóveis, dada pelo valor do choque aplicado ao sistema, processo este que perdura por 18 meses. Assim, se o choque for de 10\%, o valor real dos imóveis diminuirá em $0,53 \%$ ao mês até o mês 28 .

(10) Para maiores detalhes sobre parâmetros do modelo e condições iniciais usadas nas simulações, ver Apêndice 2 . 
A redução do preço dos imóveis reduzirá o nível de riqueza de seus proprietários, diminuindo os níveis de consumo e renda da economia, de acordo com o ciclo L1.

As equações que relacionam valor dos imóveis, riqueza, consumo e renda são as seguintes:

Consumo $=$ Renda Esperada * Propensão Marginal a Consumir - Ajuste na Renda Esperada (4)

Onde as variações na renda esperada são determinadas pelas decisões de consumo e investimento e

Ajuste na Renda Esperada $=$ Riqueza Esperada - Riqueza $*$ taxa de juros

Define-se Riqueza pela equação 6:

$$
\text { Riqueza }=\text { Ativos Totais }- \text { Débitos }
$$

Em que

Ativos Totais $=$ Ativos Financeiros em Poder do Público + Valor Real dos Imóveis

E os débitos, como pagamentos de hipotecas e despesas financeiras, dependem do valor dos imóveis, de acordo com a equação 8 :

pagamento de hipotecas e outras despesas financeiras $=700 *$ efeito sobre pagamento de hipotecas (Valor Real dos Imóveis/Valor de Referência dos Imóveis)

Essa especificação significa que os débitos de US\$ 700 bilhões, extraídos do valor previsto pela reta de regressão para 2007, serão multiplicados por uma variável de efeito (lookup), cujo valor crescerá com o valor real dos imóveis.

O ciclo de redução de preços dos imóveis (L3), ao reduzir a riqueza e assim a renda esperada dos indivíduos, criará então as condições para uma recessão (redução de consumo). Mas a recessão será eventualmente contida pelo efeito riqueza descrito pelo ciclo L2. A redução do Consumo reduzirá o fluxo de saída Redução de Ativos, o que elevará o montante de Ativos em Financeiros em Poder do Público, recompondo a riqueza e o consumo dos indivíduos, via equações (4)(7).

Para determinar a magnitude da queda dos preços dos imóveis requerida para gerar uma crise de grandes proporções nessa economia, modela-se seu grau de fragilidade financeira pela magnitude do choque sobre o ciclo L3, visto que maiores níveis de endividamento dos tomadores tendem a produzir maiores volumes de excesso de oferta no mercado de imóveis, quando a crise se inicia. A Figura 9 indica que uma queda de $10 \%$ no preço dos imóveis é suficiente para 
produzir uma queda significativa no nível de consumo (em razão da queda no nível de renda) durante aproximadamente dois anos a partir do início da crise no mês 10 da simulação.

Figura 9

Dinâmica do consumo em três cenários de queda de valor dos imóveis

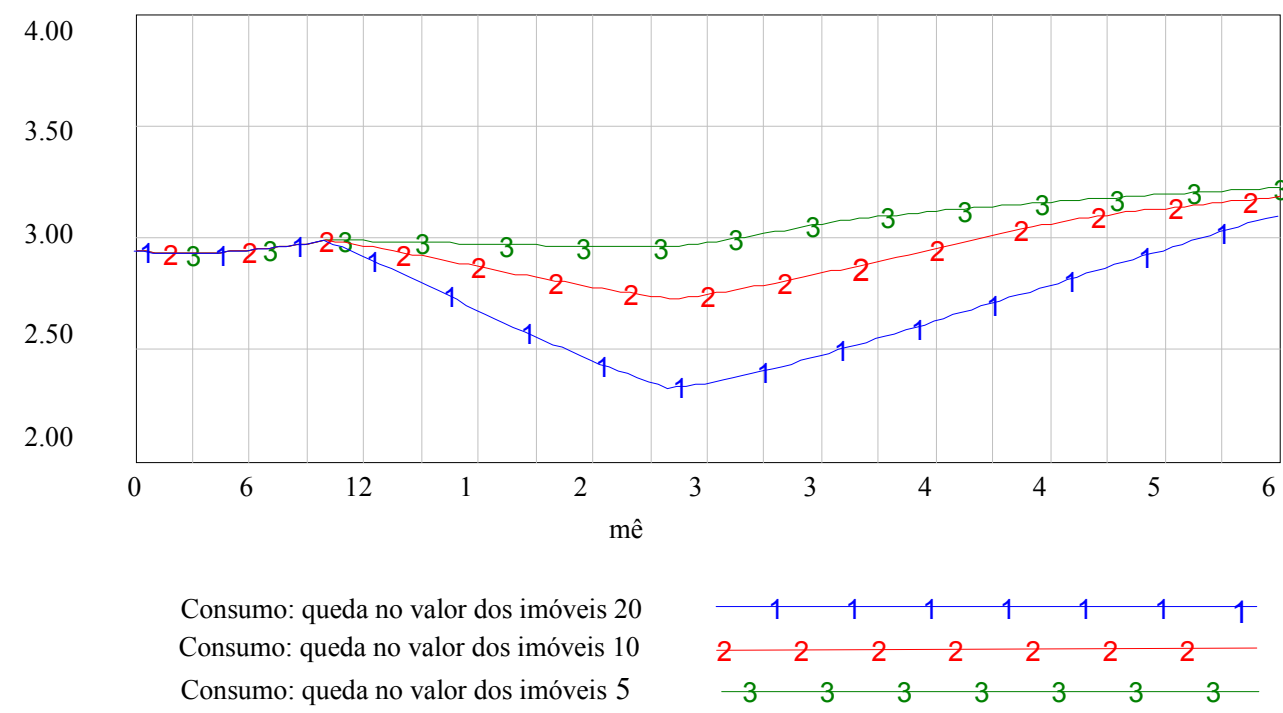

Observe-se, além disso, que baixa potência do ciclo L3, revelando reduzidos níveis de fragilidade financeira, torna a economia menos vulnerável a variações nos preços dos imóveis. Para quedas inferiores a 5\% inclusive, o consumo não chega nem mesmo a se retrair quando os preços começam a cair, o que permite definir este como o tipping point do sistema. Por que isso ocorre? A intuição econômica desse resultado é que, para variações pequenas no valor dos imóveis, a redução da renda nacional e portanto da poupança será menor do que a redução no pagamento de hipotecas e outras despesas financeiras, implicando que os indivíduos aumentarão seus estoques de ativos financeiros e, portanto, sua riqueza em um período posterior.

Esse resultado intuitivo pode ser testado com base no procedimento utilizado para estudar mudanças de dominância de ciclos de feedback no modelo epidêmico. O Quadro 1 apresenta os resultados para a análise de dominância dos ciclos L1 e L2 para o período posterior ao início da queda no valor dos imóveis. A análise de dominância do ciclo L3 deixa de ser realizada devido à suposição simplificadora de que a queda do valor dos imóveis é exógena. A importância desse ciclo, como se viu, é modelada pela magnitude do choque exógeno sobre o valor dos imóveis. 
Quadro 1

Mudanças de regime de dominância de ciclos de feedback em vários cenários de desvalorização de imóveis

\begin{tabular}{|c|l|l|}
\hline $\begin{array}{c}\text { Queda de Valor dos } \\
\text { Imóveis (\%) }\end{array}$ & \multicolumn{1}{|c|}{ Ciclo L1 } & \multicolumn{1}{c|}{ Ciclo L2 } \\
\hline 5 & Não domina & Domina a partir do mês 30 \\
\hline 10 & Domina a partir do mês 19,5 & Domina a partir do mês 48 \\
\hline 20 & Domina a partir do mês 15,5 & Domina a partir do mês 58 \\
\hline 30 & Domina a partir do mês 14,5 & Não domina no período \\
\hline
\end{tabular}

A Figura 10 ilustra a dinâmica do padrão atomístico de comportamento do consumo para dois regimes distintos de dominância de ciclos de feedback. Quando a queda do valor dos imóveis é pequena, L2 domina e a economia converge rapidamente para o equilíbrio em padrão logarítmico após o período de choque (o sinal da segunda derivada da variável Consumo é sempre negativo). Para choques de maior magnitude, por outro lado, L2 só começa a dominar a dinâmica da economia, produzindo convergência para o equilíbrio, a partir do mês 48 (o sinal negativo da segunda derivada do consumo a partir desse mês indica ajustamento em padrão logarítmico).

Figura 10

Padrão atomístico do consumo e dominância de ciclos de feedback

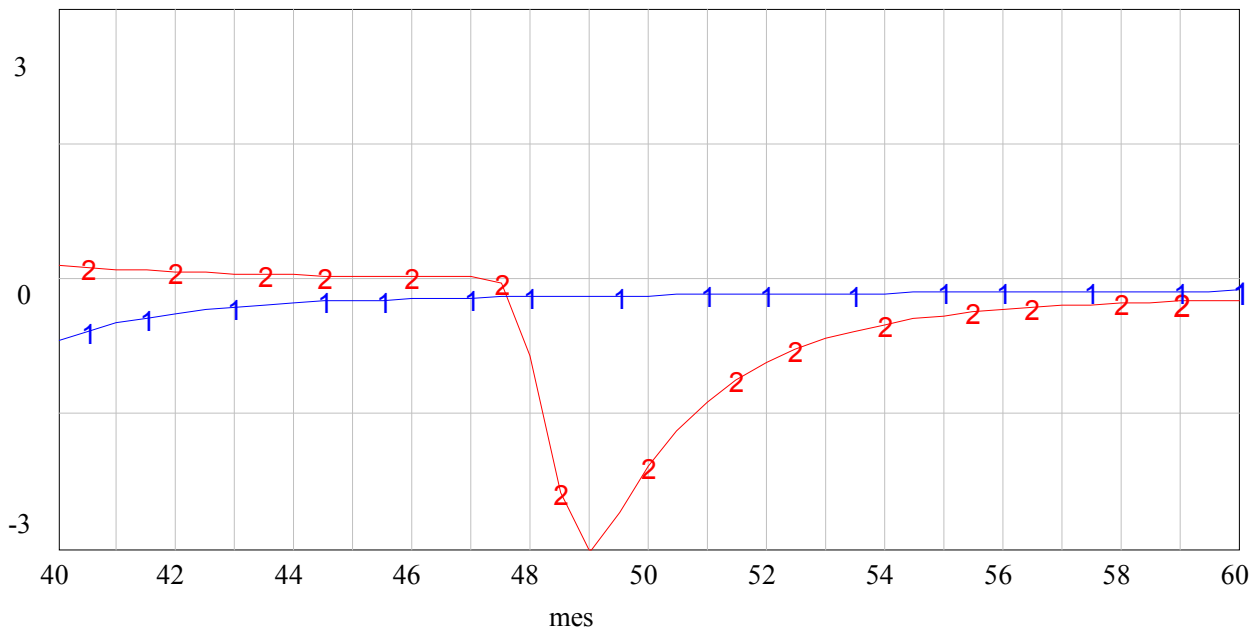

segunda derivada do consumo: queda no valor dos imóveis 5 segunda derivada do consumo: queda no valor dos imóveis 10

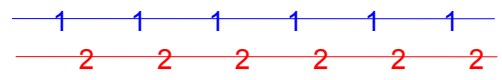

A conclusão da análise é que crises financeiras segundo a teoria em tela ocorrem porque, em economias financeiramente frágeis, o ciclo de autorreforço L1 
amplifica os efeitos de uma variação inicial dos preços dos imóveis, transmitindo esse choque predominantemente financeiro para o lado real da economia. Para verificar esse ponto, é importante reenfatizar que crises reais não chegam a ocorrer se os preços dos imóveis desvalorizarem até o máximo de $5 \%$, em que o ciclo de equilíbrio L1 não domina a dinâmica do sistema. A explicação para isso, como se viu, é que a redução inicial de riqueza é compensada pela ação de L2; isto é, os consumidores acabam compensando a perda de riqueza originada pela desvalorização dos imóveis, reduzindo o pagamento de hipotecas e outras despesas financeiras, o que contribui para aumentar seu estoque de outros ativos financeiros. Essa compensação impede que o ciclo L1 entre em ação. Para reduções superiores no valor dos imóveis, entretanto, a diminuição de riqueza provocada deixa de ser compensada rapidamente por L2, levando os consumidores a reduzirem seus níveis de consumo, o que acaba por desencadear a ação do ciclo L1. Quanto mais cedo L1 começa a dominar a dinâmica do sistema (e mais tarde L2 começa a dominar), por outro lado, maior será a queda de renda e consumo e mais tempo perdurará a recessão.

\section{Conclusão}

Uma das maiores contribuições de Minsky à teoria das crises econômicas foi mostrar que elas tendem a ocorrer endogenamente nas economias modernas, devido a dois motivos correlacionados. Em primeiro lugar, porque crises tornam-se mais prováveis quando os agentes que se financiam especulativamente - isto é, empregando esquemas de financiamento baseados em rolagem de dívidas para pagamentos dos principais ou de principais e juros (esquemas Ponzi) - passam a responder por parcela significativa das transações financeiras. E segundo porque, após períodos de prosperidade prolongada, as economias atuais tendem a transitar espontaneamente de estruturas dominadas por agentes que se financiam baseados principalmente em seus fluxos de caixa (hedge financing) para estruturas de financiamento mais frágeis, em que unidades engajadas em financiamentos especulativos tornam-se mais importantes. Nessas condições, segundo Minsky (1993, p. 7):

It can be shown that if hedge financing dominates... the economy may well be an equilibrium seeking and containing system. In contrast, the greater the weight of speculative and Ponzi finance, the greater the likelihood that the economy is a deviation amplifying system.

O objetivo central deste trabalho foi sugerir que a metodologia de dinâmica de sistemas, em geral, e a análise de dominância de ciclos de feedback, em particular, podem ajudar a dar uma melhor formalização matemática à proposição acima e, eventualmente, contribuir para desenvolver técnicas capazes de identificar com certa antecedência crises econômicas de origem financeira. $\mathrm{O}$ procedimento 
proposto consiste em identificar níveis críticos de variáveis-chave como o valor de imóveis - ou tipping points - em que ocorrem mudanças de dominância de ciclos de feedback. Dois ciclos de amplificadores (ou de autorreforço) e um ciclo de equilíbrio foram incorporados ao modelo construído no trabalho. Um dos ciclos amplificadores representa o efeito cumulativo da demanda agregada sobre a renda e, assim, transmite para o lado real da economia os efeitos financeiros do segundo ciclo amplificador, o qual relaciona os efeitos produzidos por variações patrimoniais sobre a demanda agregada. O ciclo estabilizador, por sua vez, representa o ajuste patrimonial de longo prazo induzido por reduções de renda corrente, o qual, sob certas condições, pode compensar os efeitos recessivos dos ciclos amplificadores. $\mathrm{O}$ trabalho mostrou, especificamente, que quanto mais cedo, após um choque econômico, os ciclos amplificadores começarem a dominar a dinâmica do sistema, mais pronunciados tenderão a ser os efeitos das crises financeiras sobre o assim chamado lado real da economia.

Diversas simplificações, algumas delas difíceis de justificar em trabalhos mais aplicados, foram feitas. A principal foi considerar a redução do valor dos imóveis como um processo exógeno e não realmente como um ciclo de feedback. Supôs-se, resumidamente, que em uma economia financeiramente frágil, uma pequena redução inicial do preço dos imóveis leva a uma fuga mais rápida e intensa para a liquidez (por exemplo, via execução de dívidas de agentes financiados especulativamente), intensificando o movimento descendente de preços. Modelou-se esse efeito como uma redução exógena mais acentuada no valor real dos imóveis durante os dezoito meses seguintes ao início do processo. Por essa razão, o ciclo L3, que representaria esse ingrediente fundamental da crise financeira recente, atua (domina) apenas nesse período, limitando-se a análise às alternâncias de dominância dos ciclos L1 (amplificador) e L2 (estabilizador). Os parâmetros e as condições iniciais para as simulações, por outro lado, embora baseados em dados reais da economia americana em 2007, não foram filtrados de forma mais rigorosa em termos econométricos. Como o objetivo do texto é primordialmente o de descrever os passos essenciais de uma nova metodologia, preocupou-se apenas em preservar proporções plausíveis entre parâmetros, o que em princípio assegura que as simulações não produzam resultados incompatíveis relativamente aos observáveis empiricamente, se o modelo apresentar coerência interna.

A despeito dessas limitações, as quais naturalmente necessitam ser corrigidas em trabalhos mais aplicados, a abordagem sugerida pode vir a ser útil em diversos contextos. Por exemplo, ao indicar que crises e eventualmente colapsos financeiros resultam de propriedades matemáticas relativamente simples, ela pode ajudar a desenhar políticas mais eficientes para mitigar o efeitos desses eventos. Entender seus mecanismos de preservação e evolução - os ciclos de 
feedback que comandam sua dinâmica - e identificar seus tipping points parecem constituir, portanto, um passo inicial indispensável para tornar mais administráveis as economias modernas.

\section{Referências bibliográficas}

COHEN, B. The edge of chaos: financial booms, bubbles, crashes and chaos. Chichester: John Wiley \& Sons, 1997.

COYLE, R. G. System dynamics modeling: a practical approach. London: Chapman and Hall, 1996.

DIEBOLD, F. The past, present and future of macroeconomic forecasting. Journal of Economic Perspectives, v. 12, n. 2, Spring, 1998.

; RUDEBUSCH, G. Measuring business cycles: a modern perspective. The Review of Economic and Statistics, v. 78, n. 1, 1996.

FORD, A. System dynamics and the electric power industry. System Dynamics Review, v. 13, n. 1, Spring, 1996.

FORD, D. A behavioral approach to feedback loop dominance analysis. System Dynamics Review, v. 15, n. 1, Spring, 1999.

FORRESTER, J. Urban dynamics. Waltham, MA: Pegasus Communications, 1969.

GLADWELL, M. The tipping point: how little things can make a big difference. New York: Little, Brown and Company, 2000.

HAMILTON, J. D. A new approach to the economic analysis of nonstationary time series and the business cycle. Econometrica, v. 57, n. 2, 1989.

LAVOIE, M. Introduction to post-Keynesian economics. Great Britain: Palgrave, MacMillan, 2009.

MINSKY, H. The financial instability hypothesis. In: ARESTIS, P.; SAWYER, M. (Ed.). Handbook of radical political economy. Aldershot: Edward Elgar, 1993. Disponível em: http://www.levyinstitute.org/pubs/wp74.pdf.

Press, 1986.

. Stabilizing an unstable economy. New Haven and London: Yale University . Can "it" happen again? New York: M.E. Sharpe, 1982.

PAICH, M. Understanding economic crisis. Isee Systems, Inc., 2010.

POTTER, S. A nonlinear approach to U.S. GNP. Journal of Applied Econometrics, 10, Apr./Jun. 1995.

RUDOLPH, J. W.; REPENNING, N. Disaster dynamics: understanding the role of quantity in organizational collapse. Administrative Science Quarterly, v. 47, n. 1, Mar. 2002 . 
SARGENT, T.; SIMS, C. Business cycle modeling without pretending to have too much a priori theory. In: SIMS, C. et al. New methods in business cycle research. Minneapolis: Federal Reserve Bank of Minneapolis, 1977.

SENGUPTA, N.; SWATI, S.; OSTROM, E. Sustainability, equity, and efficiency of irrigation infrastructure. In: CONSTANZA, R. Institutions, ecosystems, and sustainability. Boca Raton: Lewis Publishers, 2001.

STERMAN, J. Business dynamics. Boston: Irwin McGraw-Hill, 2000.

TAYLOR, T.; FORD, D. Tipping points failure and robustness in single development projects. System Dynamics Review, v. 22, n. 1, Spring 2006. 


\section{Apêndice 1}

\section{Documentação do modelo epidêmico}

Duração Média da Infecção $=1$

Unidades: dias

Tempo em dias de duração da doença.

Período Final $=100$

Unidades: dias

O período final da simulação.

Fluxo de População Infectada = Taxa de Contato*Grau de Infecção*População

Suscetível*(População Infectada/População Total)

Unidades: pessoas

A quantidade de pessoas infectadas por dia.

Fluxo de População Recuperada = População Infectada/Duração Média da Infecção Unidades: pessoas

A quantidade de pessoas que se curam da doença por dia.

Grau de Infecção $=0,02$

Unidades: dmnl

A probabilidade de que um indivíduo infectado contamine um indivíduo sadio ao se aproximar dele.

Período Inicial $=0$

Unidades: dmnl

Dia inicial da simulação.

População Infectada = INTEG (Fluxo de População Infectada - Fluxo de População Recuperada, 1.000)

Unidades: pessoas

A população infectada em cada momento, sendo o valor inicial $=1.000$ canadenses infectados.

População recuperada = INTEG (Fluxo de População Recuperada, 0)

Unidades: pessoas

População recuperada e portanto imunizada ao vírus.

População Suscetível = INTEG (-Fluxo de População Infectada, 1.5e+006)

Unidades: pessoas

A população total passível de ser infectada ou grupos de risco, supondo que estes possam ser identificados claramente. O valor inicial é o da população de Manhattan.

População Total $=1.5 \mathrm{e}+006$

Unidades: pessoas 
População total da cidade ou região em que a doença se espalha, no caso a população de Manhattan.

SAVEPER $=1$

Unidades: dias

Frequência com que o produto é armazenado.

Taxa de Contato $=50$

Unidades: dmnl

O número médio de pessoas que se aproximam de um indívíduo médio o suficiente para infectá-lo.

TIME STEP $=1$

Unidades: dias

O intervalo de simulação. 


\section{Apêndice 2}

Parâmetros e condições iniciais assumidos para o modelo sistêmico de crises financeiras

Todos os valores iniciais de variáveis de estoque, como a renda esperada (que é calculada a partir da renda nacional corrente) e o valor real dos imóveis, ou de variáveis exógenas (parâmetros), como outros itens de gastos (Investimentos, Gastos Governamentais e Exportações Líquidas) referem-se a valores das séries observadas da economia americana em 2007, extraída a tendência do período 1987-2007, como realizado no modelo original de Paich (2010). Assim, o valor da renda esperada de US\$ 4.000 bilhões, por exemplo, significa que a renda esperada foi US\$ 4 trilhões superior ao valor previsto pela regressão linear simples das observações no período. Observe-se que, para os objetivos do trabalho, importa mais que as relações entre parâmetros e variáveis façam sentido, do que seus valores absolutos reflitam acuradamente os valores reais da economia americana.

Os principais parâmetros e condições iniciais assumidos foram:

\begin{tabular}{|l|c|}
\hline Condições iniciais & Valor (US\$ bilhões) \\
\hline Renda Esperada & 4.000 \\
\hline Ativos Financeiros em Poder do Público & 22.300 \\
\hline Valor Real dos Imóveis & 125.400 \\
\hline Estoques Efetivos & 1.285 \\
\hline Parâmetros & 103 \\
\hline Débitos & 750 \\
\hline Outros Itens de Gastos & 1.285 \\
\hline Estoques Desejados & 0,70 (sem dimensão) \\
\hline Propensão marginal a consumir & 0,03 (sem dimensão) \\
\hline Taxa de Juros & \\
\hline
\end{tabular}

